\title{
DEVELOPING INTERNATIONAL LEADERSHIP IN EDUCATIONAL TECHNOLOGY
}

Strategies to Promote Intercultural Competence

\author{
Niki Davis ${ }^{1}$, Andrew Brown ${ }^{2}$ and Rick Ferdig ${ }^{3}$ \\ ${ }^{1}$ Iowa State University and Institute of Education University of London UK, ${ }^{2}$ Institute of \\ Education University of London UK, ${ }^{3}$ University of Florida USA
}

\begin{abstract}
Harnessing the power of new methods and new technologies is a key to renewing education to serve our diverse societies at the beginning of the twenty-first century. Doctoral education plays a pivotal role in the professional preparation of leaders for higher education, schools and related services. Drawing upon research and development in Europe and the USA, this paper describes a range of innovative strategies to promote intercultural competence. The transatlantic project International Leadership in Educational Technology (ILET) is building a virtual learning community. The project has confirmed our belief that communication technologies, blended with faculty collaboration and limited student travel, make potent ingredients for the preparation of the next generation of leaders of educational technology. However, the project has also dispelled any naïve beliefs as to our ability to effect widespread change in our universities. A second example project within Iowa State University used complementary strategies that developed project proposals taking ILET as one example of the use of technology for international education, including a future project to measure intercultural competence over time.
\end{abstract}

Key words: professional development, cultural learning, virtual learning community

\section{INTRODUCTION}

There is growing awareness of the need to develop intercultural communication and global perspectives in many countries, especially in Europe and North America. The adoption of information processing has led to global changes resulting in an urgency to increase access to educational technology (Haddad \& Draxler, 2002): that access should respect our 
culturally diverse world. This should involve expanding the education of educators and the training of the trainers to include intercultural perspectives, and to actively develop their intercultural communication. Martin \& Nakayama (2000) identify motivating factors to improve intercultural communication:

- A technology push that links an increasing diversity of cultures reduces the effects of spatial and temporal separation.

- An economic imperative as trade and commerce, including trade in education and training, becomes increasingly global in scale and aspiration whilst maintaining the need to meet local needs and concerns.

- The personal motivation that comes with our inquisitive and exploratory nature as human beings developing self-awareness. To this we add the educational enrichment of being able to critically reflect when the familiar has become strange.

- The imperative of peace and the related demographic imperative as our societies become increasingly diverse.

- Ethical imperatives that arise from the many issues that arise with variations in beliefs and norms.

These imperatives led us to collaborate to develop a range of strategies for professional development of the next generation of leaders of educational technology. Our goal is to use the medium of E-learning to spread the message of intercultural communication, especially in education and training. A significant reconceptualization has come with the realization that aspects of culture shock also apply to online learning, especially over the web. McLuhan's (1967) concept that 'the medium is the message' is relevant; digital media are not neutral and their affordances are not always expected.

\section{CULTURE SHOCK ONLINE}

Culture shock, which is commonly experienced by people when immersed in settings that are unfamiliar to them, has long been acknowledged as an important issue for those involved with international education. Such immersion presents both opportunities and significant risks. Universities routinely brief foreign students on their arrival from abroad on the U-curve of culture shock that they will experience. The start is an enjoyable tourist phase before culture shock with its disorientation, stress and anxiety. This is followed by adjustment as problem-solving skills develop, until stable adaptation or acculturation is achieved (Winkleman, 1994). Students are also warned to expect a similar less severe cycle on their return 'home.' Students preparing to study abroad are briefed on the 
phenomenon of culture shock and occasionally work through exercises to help reduce the effect. Cultural preparation includes familiarization, before departure, with foreign artefacts and problem solving behaviors accompanied by some key words for common situations, along with appropriate body language. The process of culture shock is also relevant to our research on teacher education for distance education. For example, Niki Davis leads the development of a course for preservice and practicing teachers that prepares them to teaching using a wide range of strategies in distance education. The associated research has repetitively prototyped this course (Davis \& Nilakanta, 2003). Students in this course work in groups studying cases of distance education, and the course culminates in a group project to develop their own authentic case of distance education. All or most of the course takes place in a distance learning mode using WebCT. Students find this to be very stimulating and engaging by the end of the course, and it is not unusual to find that some students wish to continue using WebCT beyond the end of semester. However, some students seem to experience elation in the early stage, followed by anxiety during which they complain about feelings of disorientation in the online classroom.

Our work to reduce culture shock for students studying abroad, has suggested to us that this emotional reaction to web-based learning may be a form of culture shock. This is supported by the literature that describes online environments in cultural terms and the term "cyberculture" (see Bonk \& King, 1998 for example). This common need to address culture shock for both eLearning and for the development of intercultural competence provides the authors of this paper with a shared focus to the two projects discussed in this paper. The first project involves a transatlantic consortium applying eLearning to doctoral education. The second project promoted the development of international projects within one university in the USA.

\section{OUR TRANSATLANTIC PARTNERSHIP}

The ILET project brings together doctoral students, faculty and staff to create an international and intercultural doctoral research and development community in educational technology in six universities; three in Europe and three in the United States. A major motivation for this project is the recognition that, whilst researchers and leaders in the use of educational technology are working in contexts that are increasingly culturally diverse, we have done little to prepare them for this. The idea of membership of and immersion in a community of researchers is central to both the European and North American notions of doctoral level study and provided, from our viewpoint, an ideal starting point for such a preparation. The extent of a 
doctoral research community is potentially huge with the use of synchronous and asynchronous communication technologies, such as email, video and text conferencing and virtual learning environments, plus the dissemination of research via the web.

Our engagement in this globally connected, but spatially and temporally distanced community, with none of the immediate existential communicative imperatives of physical immersion, can too often be from a culturally fixed and non-reflexive position. Thus the challenge facing the six participating universities is how to create contexts for intercultural interchange and interaction in which reflection on the very processes of this engagement is facilitated, and the implications are critically considered. Our aim is for all involved to be able to engage in intercultural interactions in academic and professional contexts with greater understanding, and to relate this to the development of knowledge and practice in the areas of our expertise.

One of the project's major objectives is to enable doctoral students from the USA and our European partner universities to spend one semester abroad at a project member university. This will have a profound effect on the individuals involved and begins to have an effect on the institutions on both sides of the Atlantic. Much time and effort clearly has to be given to preparation of students to make the most of this kind of experience. We have created online and other digital resources for cultural preparation and recruitment. To extend the benefits of the developing partnership between universities to students who are not intending or unable to travel, we have also developed a range of online seminars and reading groups. Our intention is to develop from this a clearer understanding of how to facilitate advanced learning and knowledge production in intercultural contexts, both face-toface and virtual. The first step in this process involved the development of mutual understanding between the staff involved in the project.

Having to develop a common understanding of educational technology, and to create the conditions for research students to cross the Atlantic, involved an exchange of perspectives and a growing understanding of the differences in our programmes and their underlying assumptions. Expectations of doctoral students are very different both within Europe and between Europe and the USA (Brown \& Dowling, 1998). If we are to facilitate mobility and productive interchange, we have to find ways to understand and handle these differences.

Our initial collaboration resulted in the production of a six way Memorandum on Understanding between the partner universities. This has laid the foundations for both movement of staff and doctoral students between the universities and the creation of a range of experiences that incorporate intercultural communication on the web, such as our series of transatlantic reading groups and opportunities to join web-based courses run 
at other universities. These, too, provide rich intercultural experiences and also present the possibility of culture shock. Their strength is that they provide a legitimate opportunity to reflect upon issues relating to cultural diversity in computer-mediated contexts. These courses and seminars, thus, both take communication technology as a focus and use it to enable intercultural interaction. This interaction in turn becomes a legitimate focus for discussion, which facilitates critical reflection on the relationship between cultural and linguistic diversity, and the characteristics and consequences of different forms of computer-mediated interaction. Online academic and professional discussions can, for instance, be every bit as socially and culturally differentiating and excluding as face-to-face encounters. The web-based component of the project enables us to explore the relationship between culture and factors such as the content of the curriculum, forms of pedagogy and the structuring and characteristics of the online environment. We have found, for instance, within the group there are strong commitments to particular educational ideologies, which relate to the cultural background of participants, and these impact on the form of online environment in which people feel most comfortable. Virtual study abroad raises many of the same issues as physical study abroad. Given the increasing ease of access to opportunities to 'study abroad' online, and the degree to which interaction on the web is increasingly intercultural, these issues become ever more pressing.

In recognition of the value of these experiences, both for individuals and institutions, we have extended our planned Certificate in Intercultural Educational Technology to include doctoral students who participate in the web-based activities and who provide mentoring and support for those who are able to take up the opportunity to travel. All participants will have the opportunity to develop reflective accounts of their intercultural experiences and develop these into an ePortfolio that can be submitted for the award of the Certificate. Since the initiation of the ILET project in autumn 2001, we have been building a rich collection of publicly available resources on the web to support faculty and participating doctoral students (http://www.public.iastate.edu/ ilet). We intend to add edited material from the ePortfolios to the ILET web site, thus supplementing our developing collection of eLearning resources with the best student material. In autumn 2002 the web site provided the home for the project's first international reading group, during which online discussions moved across professional and university E-forums on both sides of the Atlantic. The first virtual exchanges and team teaching took place and were followed by a second reading group in which readings were discussed in Spanish to establish the two main languages of the project. More are planned for the coming year. 
With the dominance of English on the web, the project is keen to support students' growing appreciation of minority languages. Danish and Catalan partners, at Aalborg University and the University of Barcelona, have been working to support study abroad by developing flexible web-based learning materials, covering culture and language. For example, in autumn 2002 two Danish interns at Iowa State University led the development of Danish materials supported by ISU students studying distance education.

An intensive course, on site in June 2003 at the Institute of Education focused on international issues in educational technology and involved students and faculty from all partner universities. It provided the opportunity to blend on site learning with eLearning and to develop links that will develop into internships and longer-term partnerships between EU and US faculty and doctoral students. In autumn 2003 the next key development occurs when the first doctoral students undertake transatlantic internships. These students will be the first ILET future leaders to become interns in higher education abroad, while continuing their doctoral research.

\section{ORGANIZATIONAL CHANGE IN A UNIVERSITY}

The ILET project has confirmed our belief that communication technologies, blended with faculty collaboration and limited student travel, make potent ingredients for the preparation of the next generation of leaders of educational technology. However, it has also dispelled any naïve beliefs as to our ability to effect widespread change in our universities, and we recognize that there will be significant challenges to sustaining and expanding our international collaboration. Universities have been termed 'organized anarchies' with local academic freedoms within traditional broad reaching legacy structures that are notoriously difficult to change.

The first author successfully led colleagues in a project to deliver workshops in planning international projects that would incorporate communication technologies to support their goals. The first workshop used project descriptions, including ILET described above, to stimulate more than six grant planning teams, which incorporated the experience of both US faculty (with academic expertise) and international graduate students (with specific international expertise). A second workshop developed an outline proposal for an overarching project to understand the ways in which the developing intercultural competence enhances higher education and later professional practice.

This future project would create tools and strategies to measure student and faculty development through the phases of culture shock with use of the 
web as a net to collect data from many international programs while simultaneously providing ongoing dissemination. The survey instrument would also be designed to promote the process of intercultural competence. The second data collection method proposed is the use of student-generated teleographies. Howard (1996) used the word teleography to define future fictional autobiographies. If an autobiography tells the story of the past, a teleography tells the story of a future and provides a guide for that individual. Students will be requested to write teleographies before and after intercultural experience, plus a final summary of their perspectives on the change. These artefacts will allow us to measure growth in various areas (Ferdig, 2002). The sharing of these teleographies between participants is likely to promote intercultural competence and to improve our understanding of this process. The ILET project team plans to pilot this research.

\section{SUMMARY}

This paper has described ongoing research and development of an international interdisciplinary community of researchers, students and professionals committed to the appropriate development of the next generation of leaders of educational technology. Such leaders should become competent for the intercultural contexts in which they will work and model good practice for those they lead and teach.

The range of strategies that we are continuing to research and develop includes plans for both traditional and novel approaches for the measurement of intercultural competence. We have also identified a new perspective on eLearning and eTraining; namely, that culture shock occurs in distance learning and measures to manage that shock have a potentially symbiotic relationship with intercultural learning.

Although simple answers are not predicted, because we understand that we are engineering change in complex and networked educational systems (Davis 2002), the quest to promote and measure intercultural competence and to expedite successful practice enhanced with new technologies is a worthy goal motivated by the same factors that motivate those who promote intercultural communication, most notably the promotion of peace, ethics and economy, plus personal and professional development.

\section{REFERENCES}

Bonk, C. J. \& King, K. S. (1998). Electronic Collaborators: Learner-Centered Technologies for Literacy, Apprenticeship, and Discourse. Erlbaum. 
Brown, A. \& Dowling P. (1998). Doing research/reading research: a mode of interrogation for education. London: Falmer.

Davis, N. E., (2002). Leadership of information technology for teacher education: a discussion of complex systems with dynamic models to inform shared leadership. Journal of Information Technology for Teacher Education, 11, 253-271.

Davis, N. E., \& Nilakanta, R. (2003). Quality @ a distance includes preservice teachers: one case- and project-based approach. In E. Stacey \& G. Davies, (Eds.) Quality Education @ a Distance. Amsterdam: Kluwer Press.

Ferdig, R. (1998). Teaching a teacher about technology: a narrative approach. Paper presented at the annual conference of the Society of Information Technology and Teacher Education, Washington DC, March.

Haddad, W. \& Draxler A., (Eds). (2003) Technologies For Education: Potential, parameters and prospects, UNESCO and Academy for Educational Development [online] http://www.aed.org/publications/TechEdInfo.html

Howard, G. S. (1996). Understanding human nature: an owner's manual. Notre Dame Indiana: Academic Publications.

Martin, J. N. \& Nakayama, T. K. (2000). Intercultural Communication in Contexts. ( $2^{\text {nd }}$ ed.) Mountain View, CA: Mayfield Publishing Company,.

McLuhan, M. (1967). The Medium is the Message. New York: Bantam.

Winkleman, M. (1994). Culture shock and adaptation. Journal of Counselling and Development, 73, 121-127.

\section{BIOGRAPHY}

Niki Davis has research interests in both teacher education and distance education. Recent research has focused the identification and development of good practice with information technology in preservice teacher education and in distance education more generally. She is the current chair of IFIP Working Group 3.3 for Research. Andrew Brown's research interests include the development of doctoral education. Rick Ferdig's research interests include development of multimedia on the Internet to improve the teaching of reading.

\section{ACKNOWLEDGMENTS}

We would like to thank ISU colleagues including Stephen Freeman, Lynn Jones, Donna Kiensler, James Mcshay and Victor Udin. The paper and a related project are supported by funds provided in Europe by the Directorate General for Education and Culture (DG EAC) and a grant from the US Department of Education (FIPSE) and the consortium members. The paper does not necessarily represent the policy of the Department of Education, and you should not assume endorsement by the US Federal Government or DG EAC. 